\title{
Effect of Alternating Magnetic Field on the Growth of Different Strains of Bacteria in the Presence of Iron Oxide Nanoparticles
}

\author{
M-Ali H. Al-Akhras ${ }^{a, *}$, B. Albiss ${ }^{a}$, M.K. QAseer $^{a}$, R. AlkhatiB ${ }^{a}$, M.A. Al-Ghbari $^{a}$ \\ AND Q. MOHAIDAT ${ }^{b}$ \\ ${ }^{a}$ Bio-Medical Physics Laboratory, Jordan University of Science and Technology, Jordan \\ ${ }^{b}$ Physics Department, Yarmouk University
}

\begin{abstract}
Inhibition in the growth of bacterial strains was observed, where the number of colonies forming units was reduced. At $3.5 \mathrm{mT}$ the stimulation in the growth of gram-negative bacterial strain was noticed. In this case the number of colony forming units was increased. The number of colonies was affected by temperature for all strains of bacteria. This ability of alternating magnetic field, combined with coated nanoparticles, to control bacteria cells constitutes a novel contribution to the finding of new useful applications in biomedicine.
\end{abstract}

DOI: 10.12693/APhysPolA.134.133

PACS/topics: iron oxide nanoparticles, bacterial growth, staphylococcus aureus, Listeria Ivanovii, Escherichia coli, Salmonella

\section{Introduction}

Electromagnetic fields are being used widely in various applications in medicine, biology, and bioelectochemistry [1]. For the past few decades scientists attempted to use magnetic field as a meteorogenic stimulus, however there is no sufficient data supporting this attempt [2]. Studies were carried out on both gram-positive and gramnegative strains in the presence of iron oxide nanoparticles (IO-NPs). The key component of the membrane which plays here a major role is the difference in thickness of peptidoglycan between both strains [3] and can cause mutations in living organisms [4].

In this work alternating magnetic (AMF) field was used in a set-up of a fairly advanced design with a homogeneous field at the center of the coil to improve the biocompatibility of the materials. In the experiments the intensities of the magnetic field were varied from 1.5 to $10.5 \mathrm{mT}$. Experiments were carried out at different temperatures, using different times of exposure to the AMF with and without the presence of IO-NPs.

\section{Materials and methods}

Sinusoidal AC magnetic field was produced by a coil made by wrapping a wire of $2.00 \mathrm{~mm}$ in diameter seven times around a non-metallic cylinder, as shown in Fig. 1 [4]. The magnetic field was relatively homogenous inside the coil, where the samples were exposed to the field of $1.5 \mathrm{mT}$ to $10.5 \mathrm{mT}$. The samples were placed in the geometrical center of the solenoid magnet where there is a uniform distribution of magnetic field lines.

*corresponding author; e-mail: alakmoh@just.edu.jo

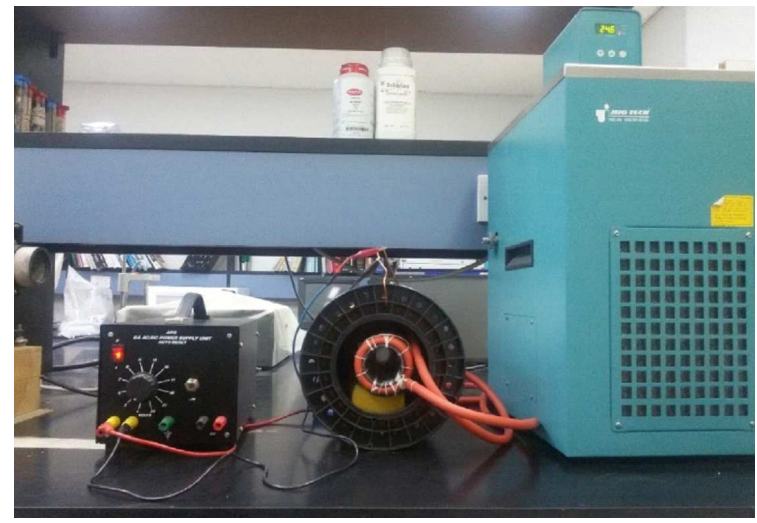

Fig. 1. Schematic diagram of the experimental setup.

The samples were placed at the center of a small cylinder inside the solenoid during the exposure. Preparation of IO-NPs was performed using procedure described previously $[5-9]$. The bacterial strains used for the determination and testing of the microbial activity were the same as those reported previously $[4,10]$.

\section{Results and discussion}

A significant increase in the average number of colonies was noticed in all samples at the presences of IO-NPs in comparison with experiments without IO-NPs. The number of colonies at $5{ }^{\circ} \mathrm{C}$ and $45^{\circ} \mathrm{C}$ was much smaller compared to those grown at $24^{\circ} \mathrm{C}$ and $37^{\circ} \mathrm{C}$. A comparable number of colonies at $24^{\circ} \mathrm{C}$ and $37^{\circ} \mathrm{C}$ was noticed. The average number of colonies of gram-positive strains is lower than the average number of colonies of gramnegative strains.

Another cause of inhibition is due to production of the reactive oxygen species which have been found in the 
metal oxide nanoparticles. These may result in oxidative stress, inflammation and consequent damage of proteins, membranes and DNA, which is one of the primary mechanisms of nanotoxicity [11]. Reactive oxygen species generated by $\mathrm{Fe}_{3} \mathrm{O}_{4}$ nanoparticles can kill bacteria without harming non-bacterial cells [12].

Higher alterations in average number of colonies were noticed under the influence of AMF at intensity of $3.5 \mathrm{mT}$, with the exception of S. aureus under $5.5 \mathrm{mT}$, which could be due to the flexibility of the membrane. A stimulatory effect of AMF on gram-negative (E. coli and Salmonella) was observed with or without the presence of IO-NPs.

The obtained results support the stimulatory observation that IO-NPs enhance the growth of bacterial strains. However, a significant reduction in the growth was observed at $3.5 \mathrm{mT}$ without IO-NPs for all strains, with the exception of $S$. aureus. However a significant effect on $S$. aureus was noticed at $5.5 \mathrm{mT}$, as shown in Fig. 2.

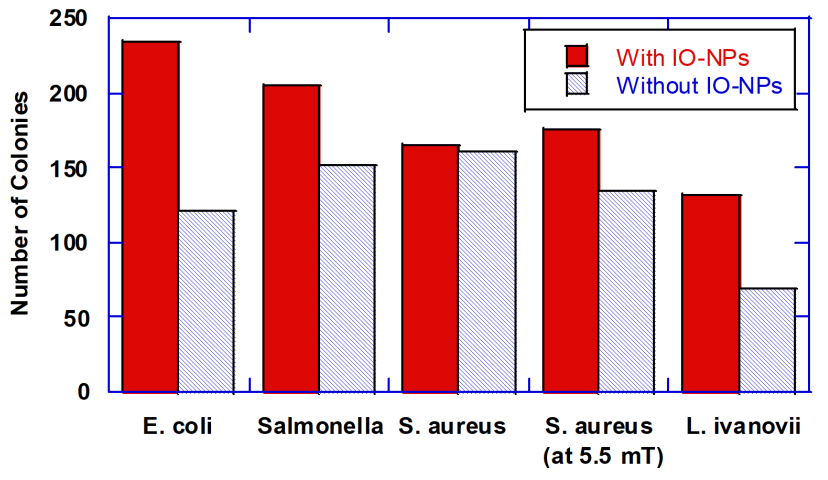

Fig. 2. Effect of AMF on the growth of bacteria strains with and without presence of IO-NPs, at $3.5 \mathrm{mT}$. Effect on $\mathrm{S}$. aureus was at $5.5 \mathrm{mT}$.

A similar alteration was noticed in gram-positive bacterial strains with the increasing time of exposure. In addition, magnetic field (MF) exposure can possibly affect the permeability of the ion transport into the cells with possible formation of free radicals and lead to biological changes within organisms [13].

Therefore, it can be proposed that MF could be used in future with combined anti-cancer and antimicrobial drugs to increase drug penetration into the cells. Thereby, further investigation for MF combined with anti-cancer and anti-microbial drugs is needed in order to optimize its pharmacodynamic and pharmacokinetic profiles [4]. Selective gram-positive bacteria displayed stronger sensitivity to MF than the selective gramnegative, both with and without IO-NPs, at all MF intensities and at all temperatures.

\section{Conclusions}

The obtained results show that gram-negative bacterial strains are more sensitive to $\mathrm{AMF}$ in comparison to gram-positive strains at all temperatures and all magnetic field intensities. The effect of AMF increases with increasing the exposure time. The IO-NPs are effective with all bacterial strains. Therefore, IO-NPs could play a major role in enhancing the growth of bacteria. The growth of bacteria was decreased at high temperature and was maximum at the optimum temperature of $25-37^{\circ} \mathrm{C}$.

\section{Acknowledgments}

This work has been supported by Jordan University of Science and Technology; Grant number (248/2014). The authors would like to thank Miss Douaa Khalili for her kind assistance.

\section{References}

[1] M. Grandolfo, Bioelectrochemistry and bioenergetics 30, 239 (1993).

[2] M. Persinger, H. Ludwig, K. Ossenkopp, Perceptual and motor skills 36, 1131 (1973).

[3] M. Singh, S. Singh, S. Prasad, I. Gambhir, Digest J. Nanomater. Biostruct. 3, 115 (2008).

[4] M.A. Aldahoun, M.S. Jaafar, M.-A.H. Al-Akhras, M. Bououdina, Artificial Cells, Nanomedicine, and Biotechnology 45, 843 (2017).

[5] K. Aljarrah, N. Mhaidat, M. Al-Akhras, A. Aldaher, B. Albiss, K. Aledealat, F.M. Alsheyab World J. Surg. Oncol. 10, 62 (2012).

[6] M.M. Masadeh, G.A. Karasneh, M.A. Al-Akhras, B.A. Albiss, K.M. Aljarah, S.I. Al-Azzam, K.H. Alzoubi, Cytotechnology 67, 427 (2015).

[7] M.-A. Al-Akhras, D.J. Al-Khalili, Jordan Journal of Biological Sciences 8(1), 55 (2015).

[8] M.-A. Al-Akhras, K. Aljarrh, B. Albiss, A.A. Bala, Mater. Sci. Eng. 99, 012003 (2015).

[9] M.-A.H. Al-Akhras, K. Aljarrah, B. Albiss, D. AlKhalili, Photodiagnosis and Photodynamic Therapy 18, 111 (2017).

[10] M. Aldahoun, M.-A. Al-Akhras, M.S. Jaafar, M. Bououdina, Artificial Cells, Nanomedicine, and Biotechnology 45, 98 (2017).

[11] K. Buyukhatipoglu, A.M. Clyne, Journal of biomedical materials research Part A 96, 186 (2011).

[12] D. Touati, Arch. Biochem. Biophys. 373, 1 (2000).

[13] L. Fojt, L. Strašák, V.R. Vetterl, J. Šmarda, Bioelectrochemistry 63, 337 (2004). 